DR. JIAN-SHENG (J-S) YE (Orcid ID : 0000-0001-5335-7896)

DR. MANUEL DELGADO-BAQUERIZO (Orcid ID : 0000-0002-6499-576X)

Article type : Primary Research Articles

\title{
Multifunctionality debt in global drylands linked to past biome and climate
}

Running head: Legacy effects on dryland multifunctionality

Jian-Sheng $\mathrm{Ye}^{1^{*}}$, Manuel Delgado-Baquerizo ${ }^{2,3}$, Santiago Soliveres $^{4}$ and Fernando T. Maestre ${ }^{3}$

${ }^{1}$ State Key Laboratory of Grassland Agro-ecosystems, School of Life Sciences, Key

Laboratory for Semi-Arid Climate Change of the Ministry of Education, Lanzhou University, No. 222, South Tianshui Road, Lanzhou 730000, China

${ }^{2}$ Cooperative Institute for Research in Environmental Sciences, University of Colorado, Boulder, CO 80309, USA.

${ }^{3}$ Departamento de Biología y Geología, Física y Química Inorgánica, Escuela Superior de Ciencias Experimentales y Tecnología, Universidad Rey Juan Carlos, Calle Tulipán Sin Número, Móstoles 28933, Spain.

${ }^{4}$ Departamento de Ecología, Universidad de Alicante, 03690 San Vicente del Raspeig (Alicante), Spain.

This article has been accepted for publication and undergone full peer review but has not been through the copyediting, typesetting, pagination and proofreading process, which may lead to differences between this version and the Version of Record. Please cite this article as doi: $10.1111 /$ gcb. 14631

This article is protected by copyright. All rights reserved. 
Correspondence to: J.-S. Y.; telephone, +86 13919145033; email address, yejsh@ 1 lzu.edu.cn

Keywords: plant productivity, plant species richness, precipitation, arid climate, last glacial maximum, nutrient stocks, nutrient transformation rates, palaeoclimate

Paper type: Primary Research Article

\begin{abstract}
Past vegetation and climatic conditions are known to influence current biodiversity patterns. However, whether their legacy effects affect the provision of multiple ecosystem functions, i.e. multifunctionality, remains largely unknown. Here we analyzed soil nutrient stocks and their transformation rates in 236 drylands from six continents to evaluate the associations between current levels of multifunctionality and legacy effects of last glacial maximum (LGM) desert biome distribution and climate. We found that past desert distribution and temperature legacy, defined as increasing temperature from LGM, were negatively correlated with contemporary multifunctionality even after accounting for predictors such as current climate, soil texture, plant species richness and site topography. Ecosystems that have been deserts since the LGM had up to $30 \%$ lower contemporary multifunctionality compared with those that were non-deserts during the LGM. In addition, ecosystems that experienced higher warming rates since the LGM had lower contemporary multifunctionality than those suffering lower warming rates, with a $\sim 9 \%$ reduction per extra ${ }^{\circ} \mathrm{C}$. Past desert distribution and temperature legacies had direct negative effects, while temperature legacy also had indirect (via soil sand content) negative effects on multifunctionality. Our results indicate that past biome and climatic
\end{abstract}

This article is protected by copyright. All rights reserved. 
conditions have left a strong "functionality debt" in global drylands. They also suggest that ongoing warming and expansion of desert areas may leave a strong fingerprint in the future functioning of dryland ecosystems worldwide that needs to be considered when establishing management actions aiming to combat land degradation and desertification.

\section{INTRODUCTION}

Ecosystem attributes and functions, such as biodiversity and nutrient cycling, are not only driven by current environmental conditions, but also by those they have experienced in the past. The climate existing thousands of years ago has left a detectable fingerprint in the current distribution of plant and microbial communities (Blonder et al., 2018; Delgado-Baquerizo, Bissett, et al., 2017; Delgado-Baquerizo et al., 2018; Pärtel et al., 2017; Weigelt, Steinbauer, Cabral, \& Kreft, 2016). Similarly, changes in land use that occurred centuries ago have been found to affect current soil carbon and nitrogen contents and cycling (Delgado-Baquerizo, Eldridge, et al., 2017; Dupouey, Dambrine, Laffite, \& Moares, 2002). Despite the growing evidence of the impacts of past legacies on the contemporary structure and functioning of terrestrial ecosystems, we lack empirical studies aiming to quantify the legacy effects of past climate and biome distribution on the current provision of multiple ecosystem functions (multifunctionality) related to nutrient stocks and their transformation rates. Quantifying these legacy effects is important not only to better understand the factors driving current variation in multifunctionality, but also to help foresee potential limitations in the provision of ecosystem services in the future derived from current rates of land degradation and climate change.

Legacy effects of past conditions on multifunctionality can be caused by long-term gains and losses of energy and nutrients accumulated over millennia (Delgado-Baquerizo, Eldridge, et al., 2017; Svenning, Eiserhardt, Normand, Ordonez, \& Sandel, 2015). Furthermore, past

This article is protected by copyright. All rights reserved. 
climate or vegetation have been found to affect current patterns of soil texture and plant traits globally (Blonder et al., 2018; Prentice et al., 1992). Soil texture and plant traits are known to influence ecosystem functions (Blonder et al., 2018; Prentice et al., 1992). For example, loamy soils can carry over moisture from the wet season into the dry season for plant production more effectively than sandy soils (Prentice et al., 1992). Therefore, the legacy of past conditions on multifunctionality can also be indirectly mediated by changes in variables including soil texture (Prentice et al., 1992), plant functional traits (Blonder et al., 2018) and microbial communities (Delgado-Baquerizo, Bissett, et al., 2017). Differentiating between these direct and indirect effects is of crucial importance to better quantify which part of legacy effects can be managed for (i.e., those mediated by biodiversity) from those that cannot be buffered (i.e., the direct effect of past biome and climate conditions).

Global drylands, including hyper-arid, arid, semi-arid and dry-subhumid ecosystems, have been projected to experience higher warming rates with ongoing climate change than humid areas (Huang, Yu, Dai, Wei, \& Kang, 2017). Increases in aridity due to ongoing global warming will increase the global extent of drylands, which already cover $\sim 45 \%$ of the terrestrial surface (Prăvălie, 2016), by 11-23\% by the end of this century (Huang, Yu, Guan, Wang, \& Guo, 2016). Such aridification will threaten the livelihoods of people living in these areas, particularly in the developing world, and will exacerbate the risk of land degradation and desertification, which are already negatively affecting 250 million people (Reynolds et al., 2007).

Given the inherently slow dynamics of soil nutrient buildup and plant productivity in drylands compared to other ecosystems (Fischer \& Turner, 1978; Huang et al., 2017), we would expect strong negative legacy effects of past biome and climate conditions on current multifunctionality levels, i.e. a "functionality debt". The desert biome is characterized by low vegetation cover, and thus high soil erosion rates and low nutrient contents (Borrelli et al.,

This article is protected by copyright. All rights reserved. 
2017; Olson et al., 2001; Ray \& Adams, 2001). Therefore, ecosystems under a desert biome thousands of years ago should have lower multifunctionality than ecosystems under a more mesic biome in the same period, regardless of their current climate and biome. However, the impact of these legacy effects on dryland multifunctionality, as well as whether these effects are biodiversity- and soil texture-dependent, remains to be evaluated. Moreover, the relative importance of functionality debts vs. current climate and biome as drivers of contemporary multifunctionality is largely unknown.

To address these gaps in our knowledge, we coupled data from a field survey of 236 drylands from six continents (Figure 1) to existing databases on the historical distribution of past biomes and climates (Fick \& Hijmans, 2017; Olson et al., 2001; Ray \& Adams, 2001) to evaluate the legacy effects of desert distribution and climate during the last glacial maximum (LGM, about 22000 years ago) on current multifunctionality levels. Weigelt et al. (2016) suggested that glacial conditions have been more common than interglacial conditions during recent evolutionary time. The distribution of biomes during the LGM is representative of the dominant environmental conditions (including climate) during this period (Pärtel et al., 2017). Therefore, the LGM biome distribution is likely to have a strong legacy effect on current multifunctionality levels. We hypothesized that areas that have been under the desert biome during LGM should have a reduced contemporary multifunctionality compared to current deserts that were not so during the LGM (i.e. they exhibit a functionality debt). Furthermore, Maestre et al. (2012) found that multifunctionality was reduced with increasing temperature in global drylands. Therefore, we also hypothesized that current drylands that have suffered higher increases in temperature since the LGM will have lower multifunctionality when compared to those that have undergone lower warming rates.

This article is protected by copyright. All rights reserved. 


\section{MATERIALS AND METHODS}

\subsection{Study sites}

We used data from a global field survey conducted in 236 dryland ecosystems from 19 countries (Figure 1, see also Table S1 in Supporting Information and Data S1). Our field survey was limited by funding, accessibility to locations and geopolitical and safety circumstances. Because of these, a truly global random sampling covering all dryland locations worldwide was not possible. Nevertheless, our sampling aimed to cover a large range of the environmental conditions and soil/vegetation types found in dryland ecosystems worldwide. The 236 studied ecosystems cover a mean annual temperature (MAT) ranging from -1.8 to $28.2^{\circ} \mathrm{C}$, and a mean annual precipitation (MAP) ranging from 66 to $1219 \mathrm{~mm}$. They also cover over 25 categories of soil types from the FAO classification, including all main types present in drylands (Maestre et al., 2012). The vegetation types surveyed include grasslands, shrublands and savannas, and plant species richness varies from 1 to 52 species per $900 \mathrm{~m}^{2}$.

\subsection{Field survey}

We carried out data collection between February 2006 and December 2013 using a standardized sampling protocol. At each site, we surveyed vegetation using four 30-m-long transects located parallel and separated $10 \mathrm{~m}$ among them (see Maestre et al., 2012 for details). At each transect, we established 20 quadrats of $1.5 \mathrm{~m} \times 1.5 \mathrm{~m}$ and used the total number of perennial species found within the 80 quadrats surveyed as our estimation of species richness. We measured slope angle in situ with a clinometer. We sampled soils during the dry season in most of the sites using a stratified random procedure. At each plot, we randomly placed five 50 $\mathrm{cm} \times 50 \mathrm{~cm}$ quadrats under the canopy of the dominant perennial species and in open areas

This article is protected by copyright. All rights reserved. 
devoid of perennial vegetation. We collected a composite sample consisting of five $145 \mathrm{~cm}^{3}$ soil cores ( 0 - $7.5 \mathrm{~cm}$ depth) from each quadrat, which were bulked and homogenized in the field. When more than one dominant plant species was present, we also collected samples under the canopies of five randomly selected individuals of the co-dominant species. Thus, the number of soil samples varied between 10 and 15 per site. Back in the laboratory, we sieved soil samples using a $2 \mathrm{~mm}$ mesh and air-dried them for one month. To facilitate the comparison of results across sites, we shipped the dried soil samples from all sites to Spain (Rey Juan Carlos University) for laboratory analyses.

\subsection{Quantifying multifunctionality}

To quantify multifunctionality, we selected 12 plant and soil variables that act as surrogates of carbon $(\mathrm{C})$, nitrogen $(\mathrm{N})$ and phosphorus $(\mathrm{P})$ cycling and storage (functions hereafter). Functions related to the $\mathrm{C}$ cycle included plant productivity, soil organic $\mathrm{C}$, pentoses and hexoses. Those from $\mathrm{N}$ and $\mathrm{P}$ cycles included soil nitrate, dissolved organic $\mathrm{N}$, proteins, potential $\mathrm{N}$ transformation rate, and enzymatic activity of phosphatase, available inorganic $\mathrm{P}$, total $\mathrm{P}$ and inorganic $\mathrm{P}$. These variables are considered to be critical measures of ecosystem functioning in drylands (see Whitford, 2002 for a review). We included as many functions as possible while at the same time weighting equally for the three nutrient cycles. The functions selected include "true" ecosystem functions (sensu Reiss, Bridle, Montoya, \& Woodward, 2009), such as potential $\mathrm{N}$ transformation rate, plant productivity and the activity of phosphathase, and nutrient stocks such as soil organic $\mathrm{C}$ and total $\mathrm{P}$, which are indicators of nutrient cycling rates over the long term (Manning et al., 2018).

This article is protected by copyright. All rights reserved. 
We assessed multifunctionality following the averaging approach of Maestre et al. (2012). We averaged the $\mathrm{Z}$ scores of the 12 functions to obtain ecosystem multifunctionality. This index is statistically robust (Maestre et al., 2012) and provides a holistic and easily interpretable measure to assess changes in multifunctionality, as the higher the values for the different ecosystem functions we measured, the higher the multifunctionality (Figure S1). We acknowledge that using an a priori standardized average may not allow to discriminate when all functions are performing at similar levels from situations when one function could be strongly outperforming the others (Byrnes et al., 2014). However, all individual functions in our dataset positively correlated with multifunctionality, except for soil inorganic $\mathrm{P}(r=-0.01$, Figure S1). Moreover, we found only two negative correlations between the functions that were of some magnitude $(r=-0.34$ and -0.35$)$, suggesting that there are not strong trade-offs between our surrogates of ecosystem functioning (Table S2). None of the correlations across all 12 functions was higher than 0.6, suggesting that our dataset did not contain high redundancy among the functions studied (Table S2). Multifunctionality calculated from the 12 functions correlated well with that calculated from a dataset of 16 functions ( $r=0.88$, Figure S2), thus it did not vary much when including other functions available, such as soil total nitrogen, amino acids, aromatic compounds or potential nitrogen depolymerisation.

We measured soil functions in the laboratory as described in Methods S1 in the Supporting Information. We also measured soil $\mathrm{pH}$ with a $\mathrm{pH}$-meter in a 1:2.5 (mass:volume, soil:water) suspension, and soil sand content according to Kettler et al. (2001). For all soil variables and functions, we estimated site-level values as the mean values measured in vegetated and open areas, weighted by their respective cover at each site (Maestre et al., 2012). We used the normalized difference vegetation index (NDVI) as a surrogate for plant productivity because it acts as a proxy of photosynthetic activity and large-scale vegetation distribution (Pettorelli et

This article is protected by copyright. All rights reserved. 
al., 2005), and it shows good performance vs. other vegetation indices when used in dryland ecosystems such as those we studied (Gaitán et al., 2013). We retrieved NDVI data from the $250 \mathrm{~m}$ resolution moderate resolution imaging spectroradiometer (MODIS) aboard NASA's Terra satellites (http://daac.ornl.gov/index.shtml). We used the annual integral of NDVI (iNDVI, Ponce Campos et al., 2013) averaged for the period 2000 to 2013 as a proxy of plant productivity at our sites. These iNDVI values correlated well with the average NDVI of the images before, during and after each soil and vegetation survey (Pearson's $r=0.76$, Figure S3). We used the longer term iNDVI as these values are less influenced by short term variations in precipitation and temperature.

\subsection{Assessing biome and climatic legacies}

We obtained mean annual temperature and precipitation values for each site for both current (1970-2000) and last glacial maximum (LGM; about 22000 years ago) conditions from Worldclim (Fick \& Hijmans, 2017). We used the 2.5-minute resolution bioclimatic data for both periods, as 2.5-minute is the highest resolution available for LGM data. We defined climate legacy from LGM as the difference between current and LGM climate values for temperature and precipitation. Temperature and precipitation legacies range from $2.7^{\circ} \mathrm{C}$ to $10.7^{\circ} \mathrm{C}\left(\right.$ mean $=4.8^{\circ} \mathrm{C}$, standard deviation $\left.=1.6\right)$ and from $-300 \mathrm{~mm}$ to $+600 \mathrm{~mm}($ mean $=-14$ $\mathrm{mm}$, standard deviation $=114)$ across sites, respectively.

We used the biome maps of Olson et al. (2001) and Ray \& Adams (2001) to define current and LGM distributions of desert biomes, respectively (Figure 1), which included both tropical $(\leq 10 \%$ vegetation cover) and temperate $(\leq 20 \%$ vegetation cover) deserts. The LGM biome 
map was mainly based on plant fossil data, proxy data sources such as animal and sediment information and palaeoclimatic data (Ray \& Adams, 2001). The current biome map is based on the widely recognized global maps of floristic or zoogeographic provinces, global maps of broad vegetation types, consultations from regional experts, and current climatic data (Olson et al., 2001).

The current and LGM biome maps include 15 and 24 biomes, respectively. Therefore, we regrouped LGM biomes to match the current classifications according to Pärtel et al. (2017). The desert biome had a larger distribution during LGM than nowadays (Figure 1). Spatially, the distribution of the desert biome largely overlaps with that of arid and hyper-arid regions of the world (Figure 1). However, vegetation distributions were impacted not only by climate (Thomas \& Nigam, 2018) but also by changes in sea level, large vertebrate migrations, fire disturbance regimes or geological activity (Olson et al., 2001; Ray \& Adams, 2001; Sarnthein, 1978). Therefore, the desert biome is not synonymous with arid and hyper-arid climates (Figure 1).

We defined desert legacy as a binary variable depending on whether it was a desert (105 sites) or not (131 sites) during the LGM. Similarly, current desert distribution is a binary variable depending on whether a given site is currently a desert (63 sites) or not (173 sites). We included the two binomial variables in the statistical analyses described below. The desert biomes were delineated based on thresholds of both climate and key ecosystem properties such as vegetation cover (Olson et al., 2001; Ray \& Adams, 2001). When key ecosystem properties such as vegetation cover are pushed over given thresholds, ecosystem regime shifts are likely to occur (here from non-desert to desert, D’Odorico, Bhattachan, Davis, Ravi, \& Runyan, 2013) and its biodiversity and functions may be greatly altered (Hastings \& Wysham, 2010; Pardini, Bueno, Gardner, Prado, \& Metzger, 2010). Therefore, the binary variable of desert and non-desert should be a complement to the continuous climatic variables being studied here.

This article is protected by copyright. All rights reserved. 


\subsection{Statistical analyses}

We fitted a generalized least squares (gls) model using multifunctionality as our response variable and desert and climate legacies, current desert and climate, soil $\mathrm{pH}$ and sand content, plant species richness, and site elevation and slope as predictors. This approach allows to incorporate in the model a spatial correlation structure to account for the autocorrelation found within our 236 study sites. We evaluated gls models with different spatial correlation structures using the Akaike information criteria (AIC), and found that an exponential spatial correlation structure best described the autocorrelation within the sites surveyed. The gls does not automatically select predictive variables. Therefore, we first included all the potential predictor variables, and then simplified the fitted model using a stepwise variable selection by manually removing at each step the predictor with less explanatory power (Table 1). Finally, we selected the best model with the lowest AIC (Burnham \& Anderson, 2003; Shipley, 2009). The semivariogram of the residuals of the final model used suggested that our approach effectively removed spatial autocorrelation (Figure S4). These analyses were carried out with the $\mathrm{R}$ package “nlme” version n 3.1-137 (Pinheiro, Bates, DebRoy, Sarkar, \& Team, 2012).

We then used variation partitioning (Legendre, 2008) based on linear regression to identify the unique portion of variation in multifunctionality explained by four groups of predictors: (1) LGM desert legacy, (2) temperature and precipitation legacies, (3) current temperature, precipitation and desert distribution, and (4) other drivers (location, soil, plant, and site elevation and slope). The variation partitioning approach followed uses partial regression to partition the variance in multifunctionality with respect to the four groups of predictors. Some proportions were attributed to a particular group of predictors (unique variation) and some were shared among all predictors (shared variation). We used adjusted coefficients of determination $\left(\mathrm{R}^{2}\right)$ in the variation partitioning to account for the different number of predictors included in each of the four categories. In some cases, the adjusted $\mathrm{R}^{2}$ can be

This article is protected by copyright. All rights reserved. 
negative, which means that the predictors explained less variation than expected by chance (Legendre, 2008); we set them to zero. We used permutation tests for redundancy analysis ordination, as described in Oksanen et al. (2018), to test the significance of unique variation explained by each group; the significance of the shared variation was not testable. We conducted variation partitioning analyses using the R package "Vegan" version 2.4-5 (Oksanen et al., 2018).

We used confirmatory path analysis (CPA) to further investigate the direct and indirect (via plant species richness and soil properties) effects of current and LGM climates and desert distributions on the multifunctionality of the 236 drylands studied. CPA allows the analysis of multiple variables that can present complex dependencies among them, which enabled us to partition the direct and indirect effects of different predictors (Shipley, 2009). We developed an a priori CPA model (Figure S5) that included all the relationships based on previous knowledge of the potential relationships between our variables (Delgado-Baquerizo, Bissett, et al., 2017; Soliveres et al., 2014). We included in the CPA generalized least squares (gls) fitting of multifunctionality, plant/soil variables and their predictor variables (Figure S5). We then simplified the CPA by removing non-significant paths and selected the best model as that having the lowest AIC. The final CPA included a gls fitting using multifunctionality as response variable and the desert and temperature legacies, current temperature, soil sand content, and elevation as predictors, and a second gls fitting using soil sand content as response variable and the temperature legacy, current temperature and precipitation, and as predictors. Since we included the spatial correlation structure within all gls included in the model, CPA also effectively removed the potential autocorrelation among our sites (Figure S6). We conducted CPA using the R package “piecewiseSEM” version 2.0.2 (Lefcheck, 2016).

This article is protected by copyright. All rights reserved. 
We checked the normality of all variables before and after log- and square-root transformations using the Shapiro-Wilk test as implemented in R, version 3.5.1 (Team, 2018). We then selected the transformation that allowed a best fit to a normal distribution for each variable. To address the quadratic relationships observed between multifunctionality and both soil $\mathrm{pH}$ and site elevation (Figure $\mathrm{S} 7$ ), we included $\mathrm{x}$ and $\mathrm{x}^{2}$ terms in all statistical analyses, where $\mathrm{x}$ is either $\mathrm{pH}$ or elevation. We selected the quadratic model over the linear one if the $\Delta$ of differences in AIC between these two models, i.e. AIC linear-AIC quadratic, was larger than two (Burnham \& Anderson, 2003).

As recommended (Byrnes et al., 2014; Manning et al., 2018), and to help interpreting our results, we also repeated CPA analyses for all 12 measured functions separately to test whether the effects of climate and biome legacies were consistent on the overall multifunctionality and individual functions (Table 2). Moreover, we conducted CPA for rate- and stock-based multifunctionality, respectively, to test whether the legacy effects were consistent between nutrient stocks and their transformation rates.

Plant functional diversity is a major driver of dryland multifunctionality (Gross et al., 2017) that is also likely to be affected by past climate and biome distribution (Blonder et al., 2018). Hence, we also retrieved trait data for two key traits, plant height and specific leaf area, from the TRY database (Kattge et al., 2011) as described in Gross et al. (2017). A total of 123 of the 236 sites surveyed had trait information available (Gross et al., 2017). We also conducted a CPA using these 123 sites to control for potential indirect effects of past conditions on current multifunctionality driven by functional traits. Including trait predictors did not essentially affect our results (Figure S8). However, among the 123 sites with trait information only fifteen are desert biome currently. Such small sample sizes decreased our confidence when testing the hypothesis of functionality debt caused by desert legacies. Therefore, we only present the results using all 236 sites in the main text. We also controlled This article is protected by copyright. All rights reserved. 
for regional differences in other potential confounding factors such as human influence (i.e., population pressure and land use; Last of the Wild Data, 2005), by using the residuals after fitting multifunctionality vs. human influence index (Figure S9).

\section{RESULTS}

We found a significant negative association between desert legacy and current ecosystem multifunctionality. The mean multifunctionality was $30 \%( \pm 6 \%)$ lower in drylands that were deserts during LGM than those were not (Table 1). Temperature legacy was also negatively and significantly associated with multifunctionality; this variable was reduced by $\sim 9 \%$ per degree warming (Table 1). In other words, regardless of their past biome distribution, locations with the largest increases in temperature over the last $22 \mathrm{~K}$ years had the lowest multifunctionality. Similarly, current temperature was also negatively and significantly associated with multifunctionality, albeit the rate of decrease ( $\sim 2 \%$ lower per degree warming) was much lower than that observed with temperature legacy (Table 1). Soil sand content was negatively related to multifunctionality (Table 1).

Both desert and climate legacies explained unique and significant proportions of variation in multifunctionality (13\% in total, Figure 2). Interestingly, current climates and desert distribution explained a small $(<3 \%)$, albeit statistically significant $(P<0.01)$, unique proportion of variation. Additional environmental predictors including soil, geographical, and plant variables explained the highest unique proportion of variation in multifunctionality ( $33 \%$ ). The shared variation among all predictors was around 2\% (Figure 2).

This article is protected by copyright. All rights reserved. 
Our confirmatory path analysis explained $\sim 43 \%$ of the variation in multifunctionality (Figure 3a). It confirmed the strong negative associations between contemporary multifunctionality and past desert distribution and temperatures, even after considering major drivers of dryland multifunctionality such as current climate, soil properties, site topography, plant species richness, functional diversity and human influence (Figures 3 and S8-9). These negative associations were driven by the effects found both on nutrient stocks, such as soil organic carbon, and their transformation rates, such as plant productivity (Table 2), indicating that both were equally sensitive to legacy effects. The negative effects of desert and temperature legacies were also consistent for $60 \%$ of the individual functions (vs. only $13 \%$ positive effects, Table 2), and when including more functions in our analyses (16 instead of 12 functions, Figure S10). We found that LGM desert and temperature legacies had strong negative direct effects on multifunctionality, which were about $250 \%$ stronger than those found for current climate and desert distribution (Figure 3a). Temperature legacies also had indirect (via positive effect on soil sand content) negative effects on multifunctionality (Figure 3a). Desert and climate legacies had a 10\% larger standardized total effect (i.e. sum of indirect and direct effects) on multifunctionality than current desert and climate (Figure 3b).

Current temperature had both direct and indirect (via soil sand content) negative effects on multifunctionality (Figure 3a). It also had negative effects on about $70 \%$ of the individual functions (Table 2). Current precipitation positively and indirectly influenced multifunctionality through the effects on soil sand content, albeit its effects were only about $25 \%$ of the respective effect size of desert and temperature legacies (Figure $3 b$ ). Soil sand content negatively impacted multifunctionality (Figure 3a); it also had negative effects on seven individual functions (vs. only one positive effect, Table 2). Biodiversity had no significant effects on overall multifunctionality, although it significantly and positively impacted soil organic C, soil hexoses and soil enzymatic activity of phosphatase (Table 2).

This article is protected by copyright. All rights reserved. 
However, when multifunctionality was calculated based on a different set of functions (16 stocks and rates, Figure S10), we found a positive effect of species richness on multifunctionality.

\section{DISCUSSION}

Our work provides empirical evidence of a long-term functionality debt in global drylands promoted by legacy effects of past temperature and desert biome distribution. These results add to the increasing evidence that past conditions largely influence current ecosystem structure and functioning (Delgado-Baquerizo, Eldridge, et al., 2017; Monger et al., 2015; Ogle et al., 2015; Pärtel et al., 2017), and provide novel insights about the potential impacts of the climatic changes occurring today for future ecosystem functioning. Importantly, here we found that the negative association between legacy effects and multifunctionality was not only related to stocks but also to nutrient transformation rates, which are fundamental components of ecosystem functioning. Moreover, past legacies had always larger effects on multifunctionality than those of current biomes and climate, which cautions about the potential underestimation of the functional consequences of current warming rates, as the total effects may take some time to manifest. Climatic legacy effects were mainly driven by increases in temperature rather than by changes in rainfall, suggesting that ongoing global warming may have a more detrimental effect on the future of dryland multifunctionality than forecasted changes in rainfall patterns.

There are several mechanisms explaining the legacy effects of past biome and climate on both stock- and rate-based functions. First, past climate is known to have an effect on soil texture (our results, Prentice et al., 1992) and also on current microbial diversity and plant functional traits patterns (Blonder et al., 2018; Delgado-Baquerizo, Bissett, et al., 2017), which

This article is protected by copyright. All rights reserved. 
are important factors influencing nutrient flux rates and primary productivity in drylands (Delgado-Baquerizo et al., 2016; Gross et al., 2017). Second, past climate and biome distribution may drive biotic inputs on soils for millennia, something likely to have a substantial influence on current nutrient stocks. This has been previously observed for soil C (Delgado-Baquerizo, Eldridge, et al., 2017) and we found similar results for both $\mathrm{N}$ and $\mathrm{P}$ stocks. Third, nutrient stocks and their transformation rates are interdependent. The rates of nutrient fluxes are affected not only by current environmental factors such as climate and vegetation type, but also the size of nutrient stocks (Shen, Jenerette, Hui, \& Scott, 2016). For example, many ecosystems in drylands are $\mathrm{N}$ limited, and thus their rate of primary productivity are influenced by soil N stocks (Harpole, Potts, \& Suding, 2007). Nitrogen transformation rate is positively affected by the size of microbial biomass (Chen et al., 2017), which is generally $\mathrm{C}$ limited (Conant et al., 2011); therefore, $\mathrm{N}$ transformation rate is likely to be positively affected by soil $\mathrm{C}$ and $\mathrm{N}$ stocks, as already observed in our database (Delgado-Baquerizo et al., 2013). Therefore, changes in nutrient stocks caused by past climate and biome conditions are likely to affect current nutrient transformation rates (see Table 2). In addition to the potential mechanisms behind the legacy effects of past climate, desert biomes are characterized by low vegetation cover and productivity, high soil erosion rates, extremely slow rates of soil formation, reduced nutrient turnover and slow recovery after disturbances (Borrelli et al., 2017; Chandler, Day, Madsen, \& Belnap, 2019; Webb, 2002). These characteristics might contribute to the negative legacy effects from past desert distribution observed in our study. It has been estimated that the recovery of ecosystem functioning after anthropogenic disturbances may take from centuries to millenia in drylands (Belnap \& Warren, 2002; Lovich \& Bainbridge, 1999). Although these examples show legacy effects from relatively shorter timescales compared to that found in our study, they illustrate the inherent 
slow dynamics in ecosystem functioning typically observed in drylands, and may suggest similar slow recovery after natural disturbances such as climate variation and biome migration.

Our findings indicate that a reversal from desert to more mesic biomes may still be impacted by a functionality debt from its past condition. Recovering a disturbed ecosystem might take from centuries to thousands of years, and an interim recovery debt (the reduction of ecosystem functions occurring during ecosystem recovery after disturbance) will accumulate even if complete recovery is reached (Moreno-Mateos et al., 2017). A recent meta-analysis has shown that ecosystems recovering from anthropogenic disturbances such as agricultural transformation and mining had over $35 \%$ lower C and N stocks compared with "undisturbed" reference areas (Moreno-Mateos et al., 2017). Our results show a "functionality debt" ( 30\% decline in multifunctionality) of previous environmental conditions associated to desertified drylands, i.e. high aridity and low vegetation cover. Although they are based on past climate and biome distribution, and thus may not necessarily extrapolate into the future, they suggest that the rate of land restoration should consider this functionality debt and exceed that of land degradation by a similar amount to achieve zero net land degradation aimed by international initiatives such as the UNCCD (UNCCD, 2012).

Warming reduces soil moisture, and thus inhibits microbial activity, nutrient cycling, plant growth and vegetation cover in drylands (Foley, Costa, Delire, Ramankutty, \& Snyder, 2003; Huang et al., 2017; Yin, Roderick, Leech, Sun, \& Huang, 2014). Reduction in vegetation cover also increases soil erosion (Casermeiro et al., 2004; Wei et al., 2007), affecting soil texture and thus promoting soil-mediated temperature legacy effects. Therefore, sites experiencing higher warming rates from LGM to current climate have lower multifunctionality than those suffering lower warming rates (Figure 3). Huang et al. (2017; 2016) predicted deleterious effects of ongoing global warming on the world's drylands, including long-lasting droughts and reduced crop yields and carbon sequestration in the future. In a similar direction, our results provide

This article is protected by copyright. All rights reserved. 
empirical evidence that a warming from past to today is negatively associated with multiple functions in dryland ecosystems worldwide.

Together, our study provides novel evidence that past desert and temperature legacies have detectable imprints on the current multifunctionality of global drylands. They highlight the importance of looking not only at current but past conditions to fully understand current multifunctionality patterns in these ecosystems. Our results also suggest that ongoing climate change, which will increase the expansion of desert areas, might substantially compromise the multifunctionality of global drylands in the future, and that the rate of land restoration should exceed that of land degradation by around one third if we aim to maintain the ecosystem functions that underpin the provision of key services for the $38 \%$ of human population in a warmer, and more arid, world.

\section{ACKNOWLEDGEMENTS}

J.-S.Y. is supported by China Scholarship Council and the National Natural Science Foundation of China (31570467). MDB acknowledges support from the Marie

Sklodowska-Curie Actions of the Horizon 2020 Framework Programme H2020-MSCA-IF-2016 under REA grant agreement $n^{\circ}$ 702057. SS is supported by the Spanish Government under a Ramón y Cajal contract (RYC-2016-20604). This research is supported by the European Research Council (ERC Grant Agreements 242658 [BIOCOM] and 647038 [BIODESERT]).

This article is protected by copyright. All rights reserved. 


\section{REFERENCES}

Belnap, J., \& Warren, S. D. (2002). Patton's Tracks in the Mojave Desert, USA: An Ecological Legacy. Arid Land Research and Management, 16(3), 245-258. doi:https://doi.org/10.1080/153249802760284793

Blonder, B., Enquist, B. J., Graae, B. J., Kattge, J., Maitner, B. S., Morueta-Holme, N., . . . Violle, C. (2018). Late Quaternary climate legacies in contemporary plant functional composition. Global Change Biology, 24(10), 4827-4840. doi:doi:10.1111/gcb.14375

Borrelli, P., Robinson, D. A., Fleischer, L. R., Lugato, E., Ballabio, C., Alewell, C., . . Panagos, P. (2017). An assessment of the global impact of 21 st century land use change on soil erosion. Nature Communications, 8(1), 2013. doi:10.1038/s41467-017-02142-7

Burnham, K. P., \& Anderson, D. R. (2003). Model selection and multimodel inference: a practical information-theoretic approach: Springer Science \& Business Media.

Byrnes, J. E. K., Gamfeldt, L., Isbell, F., Lefcheck, J. S., Griffin, J. N., Hector, A., . . Emmett, D. J. (2014). Investigating the relationship between biodiversity and ecosystem multifunctionality: challenges and solutions. Methods in Ecology and Evolution, 5(2), 111-124. doi:https://doi.org/10.1111/2041-210X.12143

Casermeiro, M. A., Molina, J. A., de la Cruz Caravaca, M. T., Hernando Costa, J., Hernando Massanet, M. I., \& Moreno, P. S. (2004). Influence of scrubs on runoff and sediment loss in soils of Mediterranean climate. CATENA, 57(1), 91-107. doi:https://doi.org/10.1016/S0341-8162(03)00160-7

Chandler, D. G., Day, N., Madsen, M. D., \& Belnap, J. (2019). Amendments fail to hasten biocrust recovery or soil stability at a disturbed dryland sandy site. Restoration Ecology, O(0). doi:doi:10.1111/rec.12870

This article is protected by copyright. All rights reserved. 
Chen, J., Xiao, G., Kuzyakov, Y., Jenerette, G. D., Ma, Y., Liu, W., . . Shen, W. (2017). Soil nitrogen transformation responses to seasonal precipitation changes are regulated by changes in functional microbial abundance in a subtropical forest. Biogeosciences, 14(9), 2513-2525. doi:https://doi.org/10.5194/bg-14-2513-2017

Conant, R. T., Ryan, M. G., Ågren, G. I., Birge, H. E., Davidson, E. A., Eliasson, P. E., . . Hopkins, F. M. (2011). Temperature and soil organic matter decomposition rates-synthesis of current knowledge and a way forward. Global Change Biology, 17(11), 3392-3404.

D’Odorico, P., Bhattachan, A., Davis, K. F., Ravi, S., \& Runyan, C. W. (2013). Global desertification: Drivers and feedbacks. Advances in Water Resources, 51, 326-344. doi:https://doi.org/10.1016/j.advwatres.2012.01.013

Delgado-Baquerizo, M., Bissett, A., Eldridge, D. J., Maestre, F. T., He, J.-Z., Wang, J.-T., .. . Fierer, N. (2017). Palaeoclimate explains a unique proportion of the global variation in soil bacterial communities. Nature Ecology \& Evolution, 1(9), 1339-1347. doi:https://doi.org/10.1038/s41559-017-0259-7

Delgado-Baquerizo, M., Eldridge, D. J., Maestre, F. T., Karunaratne, S. B., Trivedi, P., Reich, P. B., \& Singh, B. K. (2017). Climate legacies drive global soil carbon stocks in terrestrial ecosystems. Science Advances, 3(4). doi:https://doi.org/10.1126/sciadv.1602008

Delgado-Baquerizo, M., Eldridge, D. J., Travers, S. K., Val, J., Oliver, I., \& Bissett, A. (2018). Effects of climate legacies on above- and belowground community assembly. Global Change Biology, in press. doi:doi:10.1111/gcb.14306

This article is protected by copyright. All rights reserved. 
Delgado-Baquerizo, M., Maestre, F. T., Gallardo, A., Bowker, M. A., Wallenstein, M. D., Quero, J. L., . . Zaady, E. (2013). Decoupling of soil nutrient cycles as a function of aridity in global drylands. Nature, 502, 672. doi:10.1038/nature12670

Delgado-Baquerizo, M., Maestre, F. T., Reich, P. B., Jeffries, T. C., Gaitan, J. J., Encinar, D., . . Singh, B. K. (2016). Microbial diversity drives multifunctionality in terrestrial ecosystems. Nature Communications, 7, 10541. doi:10.1038/ncomms 10541

https://www.nature.com/articles/ncomms 10541\#supplementary-information

Dupouey, J. L., Dambrine, E., Laffite, J. D., \& Moares, C. (2002). Irreversible Impact of past Land Use on Forest Soils and Biodiversity. Ecology, 83(11), 2978-2984. doi:https://doi.org/10.2307/3071833

Fick, S. E., \& Hijmans, R. J. (2017). WorldClim 2: new 1- km spatial resolution climate surfaces for global land areas. International Journal of Climatology, 37(12), 4302-4315. doi:https://doi.org/doi:10.1002/joc.5086

Fischer, R. A., \& Turner, N. C. (1978). Plant Productivity in the Arid and Semiarid Zones. Annual Review of Plant Physiology, 29(1), 277-317. doi:https://doi.org/10.1146/annurev.pp.29.060178.001425

Foley, J. A., Costa, M. H., Delire, C., Ramankutty, N., \& Snyder, P. (2003). Green Surprise? How Terrestrial Ecosystems Could Affect Earth's Climate. Frontiers in Ecology and the Environment, 1(1), 38-44. doi:https://doi.org/10.2307/3867963

Gaitán, J. J., Bran, D., Oliva, G., Ciari, G., Nakamatsu, V., Salomone, J., . . Maestre, F. T. (2013). Evaluating the performance of multiple remote sensing indices to predict the spatial variability of ecosystem structure and functioning in Patagonian steppes. Ecological Indicators, 34, 181-191. doi:https://doi.org/10.1016/j.ecolind.2013.05.007

This article is protected by copyright. All rights reserved. 
Grace, J. B. (2006). Structural equation modeling and natural systems. Cambridge, UK: Cambridge University Press.

Gross, N., Bagousse-Pinguet, Y. L., Liancourt, P., Berdugo, M., Gotelli, N. J., \& Maestre, F. T. (2017). Functional trait diversity maximizes ecosystem multifunctionality. Nature Ecology \& Evolution, 1, 0132. doi:https://doi.org/10.1038/s41559-017-0132

Harpole, W. S., Potts, D. L., \& Suding, K. N. (2007). Ecosystem responses to water and nitrogen amendment in a California grassland. Global Change Biology, 13(11), 2341-2348.

Hastings, A., \& Wysham, D. B. (2010). Regime shifts in ecological systems can occur with no warning. Ecology Letters, 13(4), 464-472.

doi:https://doi.org/10.1111/j.1461-0248.2010.01439.x

Huang, J., Yu, H., Dai, A., Wei, Y., \& Kang, L. (2017). Drylands face potential threat under $2{ }^{\circ} \mathrm{C}$ global warming target. Nature Climate Change, 7, 417. doi:https://doi.org/10.1038/nclimate3275

Huang, J., Yu, H., Guan, X., Wang, G., \& Guo, R. (2016). Accelerated dryland expansion under climate change. Nature Climate Change, 6, 166-171. doi:10.1038/nclimate2837

https://www.nature.com/articles/nclimate2837\#supplementary-information

Kattge, J., DÍAZ, S., LAVOREL, S., PRENTICE, I. C., LEADLEY, P., BÖNISCH, G., . . . WIRTH, C. (2011). TRY - a global database of plant traits. Global Change Biology, 17(9), 2905-2935. doi:https://doi.org/10.1111/j.1365-2486.2011.02451.x

This article is protected by copyright. All rights reserved. 
Kettler, T. A., Doran, J. W., \& Gilbert, T. L. (2001). Simplified method for soil particle-size determination to accompany soil-quality analyses. Soil Science Society of America Journal, 65(3), 849-852. doi:https://doi.org/10.2136/sssaj2001.653849x

Last of the Wild Data. (2005). Wildlife Conservation Society - WCS, Center for International Earth Science Information Network - CIESIN - Columbia University, Last of the Wild Project, Version 2, 2005 (LWP-2): Global Human Influence Index (HII) Dataset (Geographic). Palisades, NY: NASA Socioeconomic Data and Applications Center (SEDAC).

Lefcheck, J. S. (2016). piecewiseSEM: Piecewise structural equation modelling in $\mathrm{r}$ for ecology, evolution, and systematics. Methods in Ecology and Evolution, 7(5), 573-579.

Legendre, P. (2008). Studying beta diversity: ecological variation partitioning by multiple regression and canonical analysis. Journal of Plant Ecology, 1(1), 3-8. doi:https://doi.org/10.1093/jpe/rtm001

Lovich, J. E., \& Bainbridge, D. (1999). Anthropogenic Degradation of the Southern California Desert Ecosystem and Prospects for Natural Recovery and Restoration. Environmental Management, 24(3), 309-326. doi:https://doi.org/10.1007/s002679900235

Maestre, F. T., Quero, J. L., Gotelli, N. J., Escudero, A., Ochoa, V., Delgado-Baquerizo, M., . . .Zaady, E. (2012). Plant Species Richness and Ecosystem Multifunctionality in Global Drylands. Science, 335(6065), 214-218. doi:https://doi.org/10.1126/science.1215442

Manning, P., van der Plas, F., Soliveres, S., Allan, E., Maestre, F. T., Mace, G., . . Fischer, M. (2018). Redefining ecosystem multifunctionality. Nature Ecology \& Evolution, 2(3), 427-436. doi:https://doi.org/10.1038/s41559-017-0461-7

This article is protected by copyright. All rights reserved. 
Monger, C., Sala, O. E., Duniway, M. C., Goldfus, H., Meir, I. A., Poch, R. M., .. . Vivoni, E. R. (2015). Legacy effects in linked ecological-soil-geomorphic systems of drylands. Frontiers in Ecology and the Environment, 13(1), 13-19. doi:https://doi.org/10.1890/140269

Moreno-Mateos, D., Barbier, E. B., Jones, P. C., Jones, H. P., Aronson, J., López-López, J. A., ... Rey Benayas, J. M. (2017). Anthropogenic ecosystem disturbance and the recovery debt. Nature Communications, 8, 14163. doi:https://doi.org/10.1038/ncomms14163

Ogle, K., Barber, J. J., Barron- Gafford, G. A., Bentley, L. P., Young, J. M., Huxman, T. E., . . . Tissue, D. T. (2015). Quantifying ecological memory in plant and ecosystem processes. Ecology Letters, 18(3), 221-235. doi:https://doi.org/10.1111/ele.12399

Oksanen, J., Blanchet, F. G., Friendly, M., Kindt, R., Legendre, P., McGlinn, D., . . Wagner, H. (2018). Community Ecology Package. R package v. 2.4-6.

Olson, D. M., Dinerstein, E., Wikramanayake, E. D., Burgess, N. D., Powell, G. V. N., Underwood, E. C., . . Kassem, K. R. (2001). Terrestrial Ecoregions of the World: A New Map of Life on Earth. BioScience, 51(11), 933-938. doi:https://doi.org/10.1641/0006-3568(2001)051[0933:teotwa]2.0.co;2

Pärtel, M., Öpik, M., Moora, M., Tedersoo, L., Szava-Kovats, R., Rosendahl, S., . . Zobel, M. (2017). Historical biome distribution and recent human disturbance shape the diversity of arbuscular mycorrhizal fungi. New Phytologist, 216(1), 227-238. doi:https://doi.org/10.1111/nph.14695

Pardini, R., Bueno, A. d. A., Gardner, T. A., Prado, P. I., \& Metzger, J. P. (2010). Beyond the Fragmentation Threshold Hypothesis: Regime Shifts in Biodiversity Across

This article is protected by copyright. All rights reserved. 
Fragmented Landscapes. PLOS ONE, 5(10), e13666.

doi:https://doi.org/10.1371/journal.pone.0013666

Pettorelli, N., Vik, J. O., Mysterud, A., Gaillard, J.-M., Tucker, C. J., \& Stenseth, N. C. (2005). Using the satellite-derived NDVI to assess ecological responses to environmental change. Trends in Ecology \& Evolution, 20(9), 503-510. doi:https://doi.org/10.1016/j.tree.2005.05.011

Pinheiro, J., Bates, D., DebRoy, S., Sarkar, D., \& Team, R. C. (2012). nlme: Linear and nonlinear mixed effects models. $R$ package version, 3(0).

Ponce Campos, G. E., Moran, M. S., Huete, A., Zhang, Y., Bresloff, C., Huxman, T. E., . . . Starks, P. J. (2013). Ecosystem resilience despite large-scale altered hydroclimatic conditions. Nature, 494(7437), 349-352. doi:https://doi.org/10.1038/nature11836

Prăvălie, R. (2016). Drylands extent and environmental issues. A global approach. Earth-Science Reviews, 161, 259-278. doi:https://doi.org/10.1016/j.earscirev.2016.08.003

Prentice, I. C., Cramer, W., Harrison, S. P., Leemans, R., Monserud, R. A., \& Solomon, A. M. (1992). Special Paper: A Global Biome Model Based on Plant Physiology and Dominance, Soil Properties and Climate. Journal of Biogeography, 19(2), 117-134. doi:https://doi.org/10.2307/2845499

Ray, N., \& Adams, J. (2001). A GIS-based vegetation map of the world at the Last Glacial Maximum (25,000-15,000 BP). Internet Archaeology, 11. doi:https://doi.org/10.11141/ia.11.2

This article is protected by copyright. All rights reserved. 
Reiss, J., Bridle, J. R., Montoya, J. M., \& Woodward, G. (2009). Emerging horizons in biodiversity and ecosystem functioning research. Trends in Ecology \& Evolution, 24(9), 505-514. doi:https://doi.org/10.1016/j.tree.2009.03.018

Reynolds, J. F., Smith, D. M. S., Lambin, E. F., Turner, B. L., Mortimore, M., Batterbury, S. P. J., . . Walker, B. (2007). Global Desertification: Building a Science for Dryland Development. Science, 316(5826), 847-851. doi:https://doi.org/10.1126/science.1131634

Sarnthein, M. (1978). Sand deserts during glacial maximum and climatic optimum. Nature, 272, 43. doi:https://doi.org/10.1038/272043a0

Shen, W., Jenerette, D. G., Hui, D., \& Scott, L. R. (2016). Precipitation legacy effects on dryland ecosystem carbon fluxes: Direction, magnitude and biogeochemical carryovers. 12, 9613-9650. doi:https://doi.org/10.5194/bgd-12-9613-2015

Shipley, B. (2009). Confirmatory path analysis in a generalized multilevel context. Ecology, 90(2), 363-368. doi:doi:10.1890/08-1034.1

Soliveres, S., Maestre, F. T., Eldridge, D. J., Delgado-Baquerizo, M., Quero, J. L., Bowker, M. A., \& Gallardo, A. (2014). Plant diversity and ecosystem multifunctionality peak at intermediate levels of woody cover in global drylands. Global Ecology and Biogeography, 23(12), 1408-1416. doi:https://doi.org/10.1111/geb.12215

Svenning, J.-C., Eiserhardt, W. L., Normand, S., Ordonez, A., \& Sandel, B. (2015). The Influence of Paleoclimate on Present-Day Patterns in Biodiversity and Ecosystems. Annual Review of Ecology, Evolution, and Systematics, 46(1), 551-572. doi:https://doi.org/10.1146/annurev-ecolsys-112414-054314

This article is protected by copyright. All rights reserved. 
Team, R. C. (2018). R: A Language and Environment for Statistical Computing, R Foundation for Statistical Computing, Austria, 2015. In: ISBN 3-900051-07-0: URL http://www. R-project. org.

Thomas, N., \& Nigam, S. (2018). Twentieth-Century Climate Change over Africa: Seasonal Hydroclimate Trends and Sahara Desert Expansion. Journal of Climate, 31(9), 3349-3370. doi:https://doi.org/10.1175/jcli-d-17-0187.1

Trabucco, A., \& Zomer, R. J. (2009). Global Aridity Index (Global-Aridity) and Global Potential Evapo-Transpiration (Global-PET) Geospatial Database. CGIAR Consortium for Spatial Information. Published online, available from the CGIAR-CSI GeoPortal at: http://www.csi.cgiar.org. Retrieved from: http://www.csi.cgiar.org

UNCCD. (2012). Zero Net Land Degradation. A Sustainable Development Goal for Rio+ 20. Policy Brief, May.

Webb, R. H. (2002). Recovery of Severely Compacted Soils in the Mojave Desert, California, USA. Arid Land Research and Management, 16(3), 291-305. doi:https://doi.org/10.1080/153249802760284829

Wei, W., Chen, L., Fu, B., Huang, Z., Wu, D., \& Gui, L. (2007). The effect of land uses and rainfall regimes on runoff and soil erosion in the semi-arid loess hilly area, China. Journal of Hydrology, 335(3), 247-258. doi:https://doi.org/10.1016/j.jhydrol.2006.11.016

Weigelt, P., Steinbauer, M. J., Cabral, J. S., \& Kreft, H. (2016). Late Quaternary climate change shapes island biodiversity. Nature, 532, 99. doi:https://doi.org/10.1038/nature17443

Whitford, W. G. (2002). Ecology of desert systems: Elsevier.

This article is protected by copyright. All rights reserved. 
Yin, D., Roderick, M. L., Leech, G., Sun, F., \& Huang, Y. (2014). The contribution of reduction in evaporative cooling to higher surface air temperatures during drought. Geophysical Research Letters, 41(22), 7891-7897. doi:https://doi.org/10.1002/2014GL062039

\section{Supporting Information}

Additional Supporting Information, including Figures S1-10, Method S1 and Tables S1 and S2, may be found online in the supporting information tab for this article.

\section{Data availability}

Data in the support of these findings (Data S1) and the R code for the statistical models conducted are available in figshare (DOI 10.6084/m9.figshare.7570925, https://figshare.com/s/4985715ce88482a9c460).

This article is protected by copyright. All rights reserved. 
Table 1 Coefficients of the generalized least squares model fitted to assess the effect of different predictor variables on ecosystem multifunctionality. This model included a spatial correlation structure to account for the autocorrelation present within the 236 sites surveyed. We also removed the predictors with low power and the final model had the lowest Akaike information criteria (see Methods section for details). The predictor variables with significant explanatory power $(P<0.05)$ included desert legacy, mean annual temperature (MAT) legacy, current MAT, soil sand content, and site elevation (Elevation ${ }^{2}$, square of elevation).

\section{Predictor Coefficients}

\section{$P$-value}

variables (mean \pm standard error)

Intercept $\quad 1.591 \pm 0.170<0.001$

Desert legacy $\quad-0.295 \pm 0.061 \quad<0.001$

MAT legacy $\quad-0.085 \pm 0.017 \quad<0.001$

$\begin{array}{lll}\text { Current MAT } & -0.021 \pm 0.006 & <0.001\end{array}$

Soil sand content $\quad-0.011 \pm 0.001 \quad<0.001$

$\begin{array}{lll}\text { Elevation }^{2} & 0.001 \pm 0.000 & 0.009\end{array}$

This article is protected by copyright. All rights reserved. 
Table 2 The total standardized effects (direct + indirect) of desert legacy, climate legacy, and current desert and climate on 12 individual ecosystem functions, based on the significant path coefficients $(P<0.05)$ of confirmatory path analyses. SOC, soil organic carbon; PEN, soil pentoses; iNDVI, annual integral of normalized difference vegetation index; HEX, soil hexoses; NIT, soil nitrate; DON, soil dissolved organic nitrogen; PRO, soil proteins; NTR, soil potential nitrogen transformation rate; AVP, soil available inorganic phosphorus; FOS, soil enzymatic activity of phosphatase; TP, soil total phosphorus; IOP, soil inorganic phosphorus; MAT, mean annual temperature; MAP, annual precipitation; Species, plant species richness; Sand, soil sand content; and site elevation (Elevation ${ }^{2}$, square of elevation).

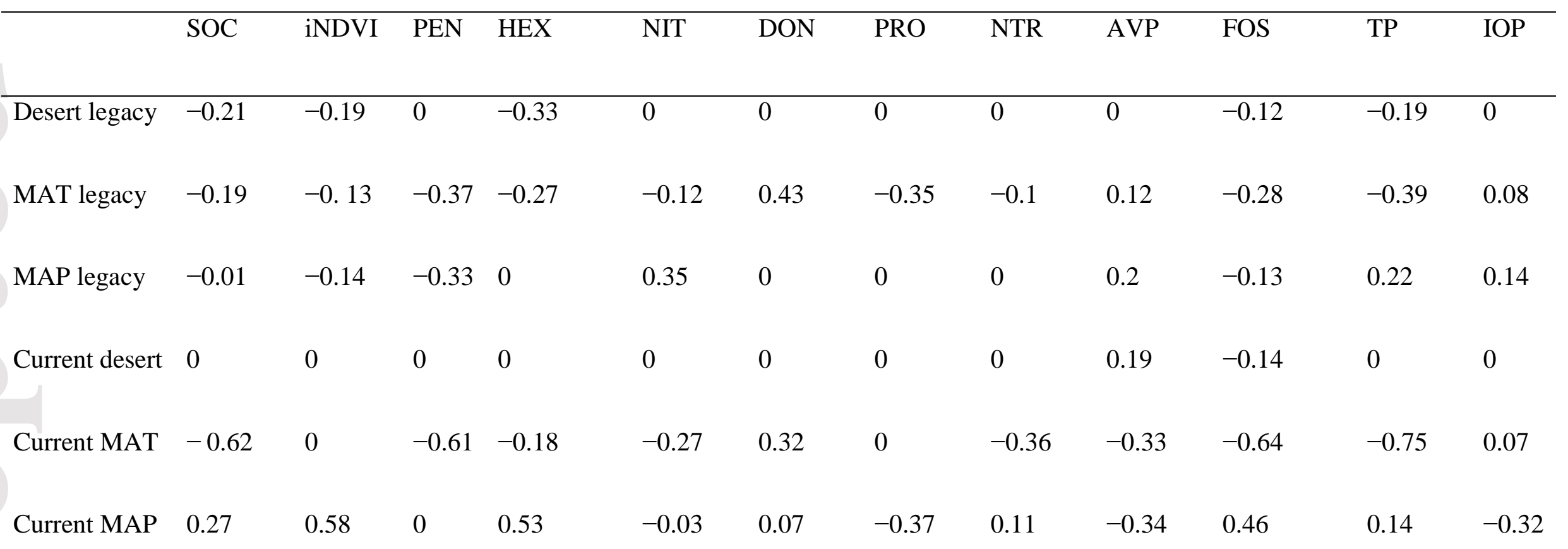

This article is protected by copyright. All rights reserved. 


\begin{tabular}{|c|c|c|c|c|c|c|c|c|c|c|c|c|}
\hline Species & 0.16 & 0 & 0 & 0.1 & 0 & 0 & 0 & 0 & 0 & 0.09 & 0 & 0 \\
\hline Sand & -0.47 & 0 & 0 & -0.16 & -0.32 & -0.16 & 0 & -0.24 & 0 & -0.34 & -0.3 & 0.21 \\
\hline $\mathrm{pH}$ & 0.31 & 0 & 0 & 0.2 & 0 & 0 & 0.24 & 0 & 0 & 0.28 & 0 & 0 \\
\hline Elevation & -0.09 & 0.48 & -0.52 & -0.05 & -0.14 & 0.44 & 0.68 & 0 & 0 & 0 & 0 & 0 \\
\hline Elevation $^{2}$ & 0.23 & -0.74 & 0 & -0.08 & -0.16 & -0.07 & -0.67 & -0.32 & 0 & -0.55 & -0.14 & 0.1 \\
\hline
\end{tabular}




\section{Figure captions}

Figure 1 Geographic locations of the 236 dryland sites surveyed and distribution of global desert biomes and drylands. The desert biomes under the Last Glacial Maximum (a) and current environmental conditions (b) were obtained from Ray \& Adams (2001) and Olson et al. (2001), respectively. The current extent of drylands, as defined by the aridity index (AI, the ratio of precipitation to potential evapotranspiration), is shown in panel (c) (source: Trabucco \& Zomer, 2009). Drylands include arid and hyper-arid $(\mathrm{AI}<0.2)$, semi-arid $(0.2 \leq \mathrm{AI}<0.5)$ and dry sub-humid $(0.5 \leq \mathrm{AI}<0.65)$ regions.

Figure 2 The unique and shared proportions of variations in multifunctionality explained by different predictors. We used variation partitioning analysis to calculate the proportions of variations. Significance levels are as follows: $* * * P<0.001, * * P<0.01$. The significance of the shared variation could not be statistically tested. The unexplained residual variance was 0.49 .

Figure 3 Confirmatory path analysis (CPA) accounting for the direct and indirect effects of environmental predictors on multifunctionality. (a) The significant path coefficients, describing the strength and sign of the relationships among the variables, are shown adjacent to the arrows (significance levels as follows: $* * * P<0.001, * * P<0.01, * P<0.05$ ). Paths of site elevation and slope were not included for simplicity, since the main objective of this study was to evaluate the legacy effects of climate and biome. MAT: mean annual temperature; MAP: annual precipitation; Soil sand: soil sand content. The CPA conducted had a Fisher's C $=5.57$, four degrees of freedom and a $P$-value $=0.23$, suggesting that it had a good fit to our data (Grace, 2006). (b) Standardized total (direct + indirect) effects of desert and climate legacies, and of current desert and climate on multifunctionality, based on CPA.

This article is protected by copyright. All rights reserved. 

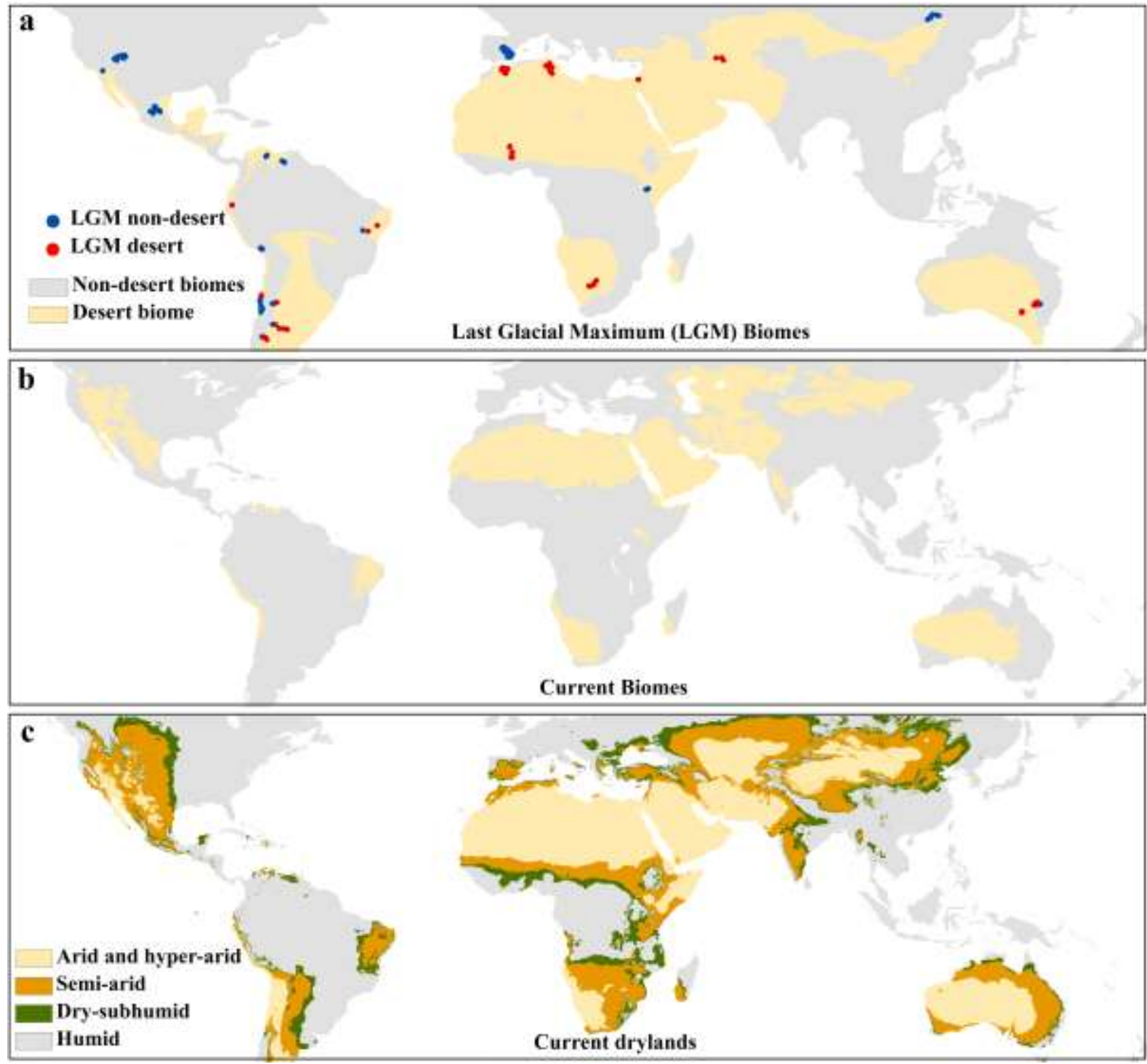

This article is protected by copyright. All rights reserved. 


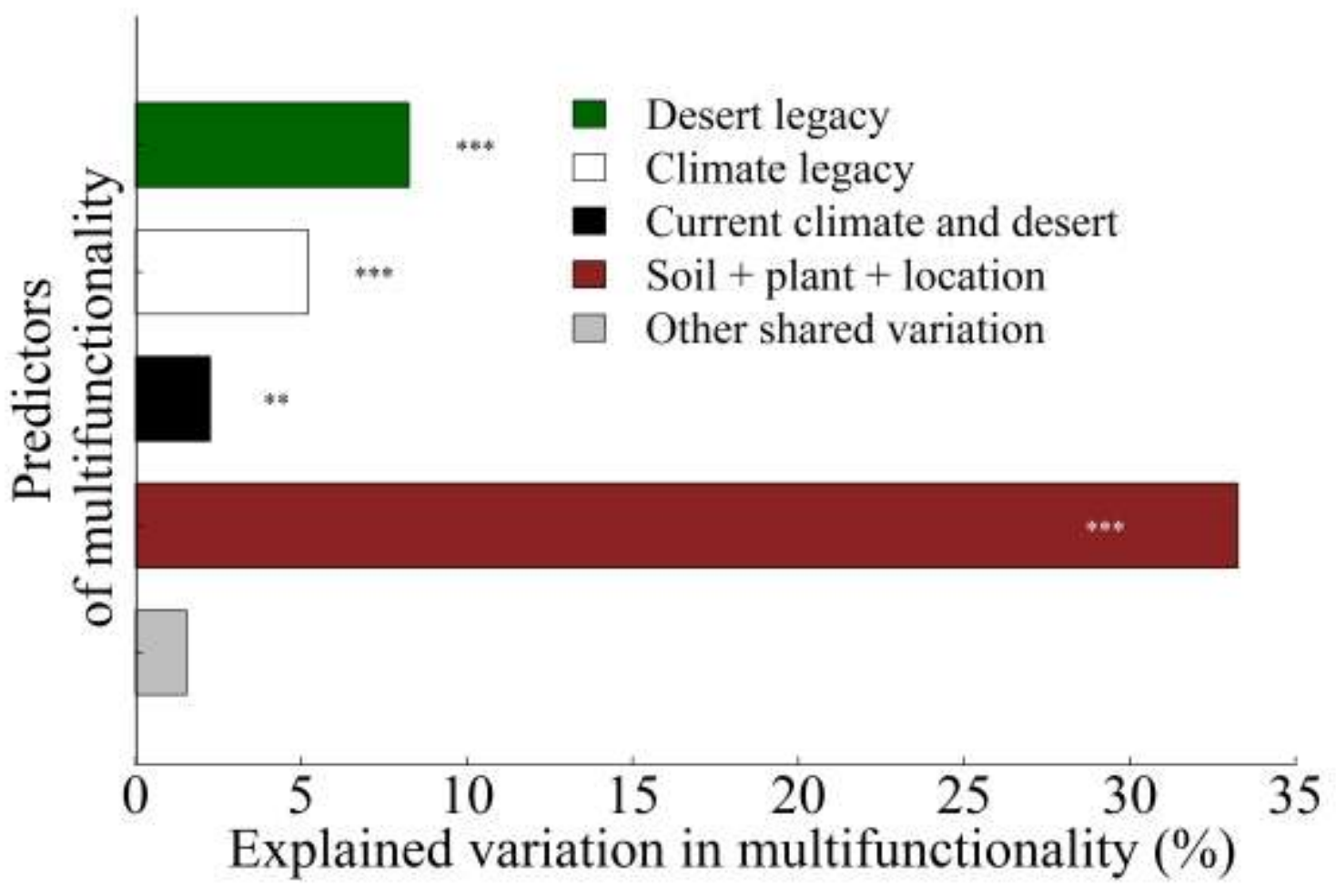

This article is protected by copyright. All rights reserved. 


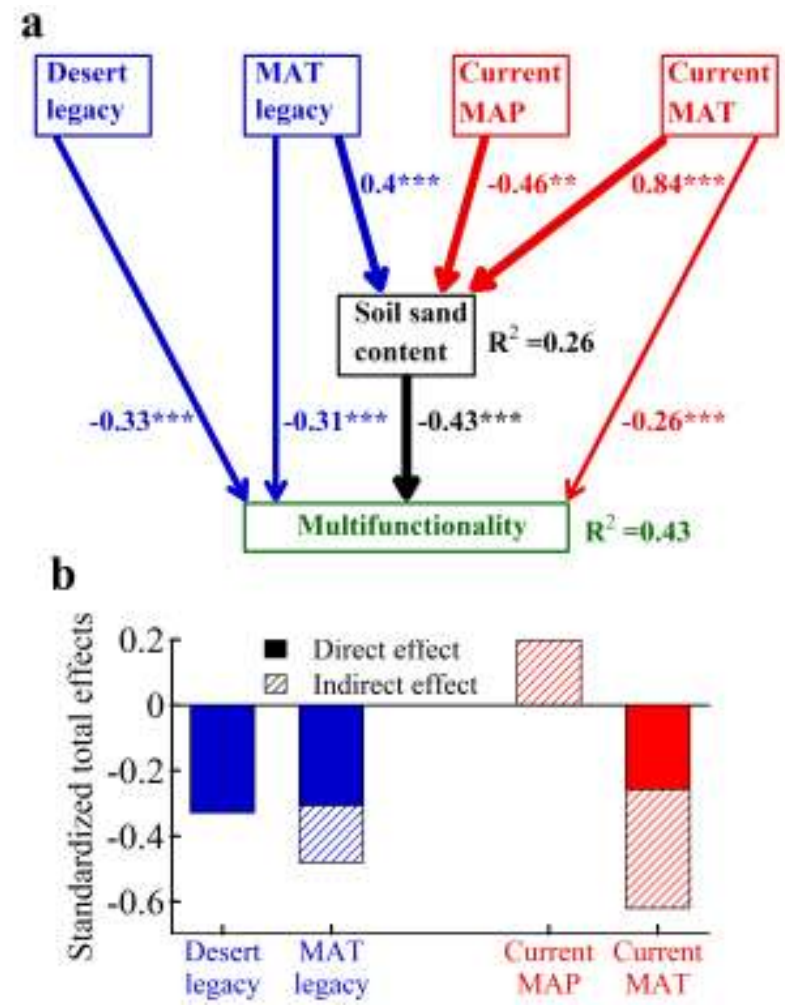

This article is protected by copyright. All rights reserved. 